\title{
Association between acute respiratory disease events and the MUC5B promoter polymorphism in smokers
}

\author{
Samuel Y Ash, ${ }^{1}$ Rola Harmouche, ${ }^{2}$ Rachel K Putman, ${ }_{1}^{1}$ James C Ross, ${ }^{2}$ \\ Fernando J Martinez, ${ }^{3}$ Augustine M Choi, ${ }^{3}$ Russell P Bowler, ${ }^{4}$ Elizabeth A Regan, ${ }^{5}$ \\ Jeffrey L Curtis, ${ }^{6,7}$ MeiLan K Han, ${ }^{6}$ Richard C Boucher, ${ }^{8}$ Wanda K O'Neal, ${ }^{8}$ \\ Hiroto Hatabu, ${ }^{9}$ David A Lynch, ${ }^{10}$ Ivan 0 Rosas, ${ }^{1}$ Gary M Hunninghake, ${ }^{1}$ \\ Raul San Jose Estepar, ${ }^{2}$ George R Washko, ${ }^{1}$ the COPDGene Investigators
}

\begin{abstract}
- Additional material is published online only. To view please visit the journal online (http://dx.doi.org/10.1136/ thoraxjn-2017-211208).

For numbered affiliations see end of article.

\section{Correspondence to}

Dr Samuel Y Ash, Division of Pulmonary and Critical Care Medicine, Department of Medicine, Brigham and Women's Hospital, Boston, MA 02115, USA;

syash@bwh.harvard.edu
\end{abstract}

Received 24 October 2017 Revised 23 January 2018 Accepted 29 January 2018 Published Online First 13 February 2018

Check for updates

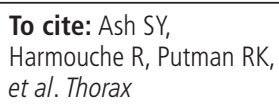

\begin{abstract}
A single-nucleotide polymorphism (rs35705950) in the mucin 5B (MUC5B) gene promoter is associated with pulmonary fibrosis and interstitial features on chest $C T$ but may also have beneficial effects. In non-Hispanic whites in the COPDGene cohort with interstitial features $(n=454)$, the MUC5B promoter polymorphism was associated with a $61 \%$ lower odds of a prospectively reported acute respiratory disease event $(P=0.001)$, a longer time-to-first event $(H R=0.57 ; P=0.006)$ and $40 \%$ fewer events $(P=0.016)$. The MUC5B promoter polymorphism may have a beneficial effect on the risk of acute respiratory disease events in smokers with interstitial CT features.
\end{abstract}

\section{INTRODUCTION}

A specific single-nucleotide polymorphism (rs35705950) in the MUC5B promoter increases the expression of MUC5B and is associated with idiopathic pulmonary fibrosis as well as with more subtle visual and objective parenchymal abnormalities on the chest CT scans of smokers. ${ }^{1-3}$ Although the fibrotic risk associated with this polymorphism is clear, its prevalence in whites and the importance of MUC5B in airway defence raise the question of whether the polymorphism may have shorter-term beneficial effects on airway clearance and acute respiratory illnesses at the expense of a longer-term risk of fibrosis. ${ }^{4-6}$ We therefore hypothesised that the rs35705950 polymorphism might decrease the risk of acute respiratory disease (ARD) events in smokers and that this effect would be most evident in those with interstitial features on chest CT as these may represent phenotypic evidence of increased MUC5B expression in some cases.

\section{METHODS}

Detailed methods are provided in the online Supplementary file 1. Briefly, using data from the COPDGene study, we measured the percentage of lung occupied by interstitial and emphysematous features using a previously described automated method. ${ }^{3}$ We defined participants as having interstitial and/or emphysematous features if those features occupied $>10 \%$ of their lung volume and performed sensitivity analyses using a 5\% threshold. ${ }^{3}$ ARD events occur in smokers with and without COPD and were defined as intermittent episodes of increased shortness of breath, cough and/or change in sputum quality requiring a change in treatment, including antibiotics and/or steroids. ${ }^{7}$ ARD events were assessed prospectively and were categorised as severe if they required an emergency room visit or hospitalisation. ${ }^{7}$ Due to the small number of participants who were homozygous for the minor allele (TT, $\mathrm{n}=53(0.8 \%))$, participants were considered to have the MUC5B promoter polymorphism if they had at least one copy of the minor allele. Secondary analyses of the primary outcomes assuming an additive effect of the number of copies of the minor allele were also performed. In addition, due to concern that the effect of each feature type may confound the relationship between the other and ARD events, secondary analyses were also performed in which the effect of each parenchymal feature type was evaluated in those with otherwise 'normal' parenchyma, that is, the effect of interstitial features was evaluated in those without emphysema, and the effect of emphysema was evaluated in those without interstitial features. Finally, due to racial differences in the prevalence of the MUC5B promoter polymorphism, all analyses were stratified by race and the primary analyses were performed in non-Hispanic whites (NHW) (minor allele frequency in $\mathrm{NHW}=19.0 \%$, in blacks $=4.4 \%$ ).

\section{RESULTS}

As shown in the online Supplementary table E1, 6863 participants had completed clinical, imaging and genetic data, of which $72.8 \%$ were NHW $(n=4999)$. As shown in the online Supplementary table E2), 43.4\% of NHW $(n=2167)$ reported an ARD event over a mean of 6.0 years of follow-up, with a mean total number of events of 2.3. In NHW with interstitial features $(n=454)$, those who had the MUC5B promoter polymorphism $(n=97)$ had a $61 \%$ lower odds of an ARD event than those without the polymorphism (OR 0.39 ; $95 \%$ CI 0.22 to 0.69 , $\mathrm{P}=0.001)$. Those with the polymorphism also had a longer time-to-first ARD event (HR 0.57; 95\% CI 0.38 to $0.85, \mathrm{P}=0.006)$ and reported $40 \%$ fewer $\mathrm{ARD}$ events (incidence rate ratio $=0.60 ; 95 \% \mathrm{CI}$ 0.40 to $0.91, \mathrm{P}=0.016$ ) (table 1 ). Similar results were found using an additive genetic model (online Supplementary table E3). NHW individuals with interstitial features who had the MUC5B promoter polymorphism also exhibited a lower odds of severe ARD event than those without the polymorphism (OR 0.48; 95\% CI 0.23 to $0.97, \mathrm{P}=0.042$ ) (online 
Table 1 Effect of MUC5B genotype on acute respiratory disease events: results stratified by parenchymal feature type

\begin{tabular}{|c|c|c|c|c|c|c|}
\hline & \multicolumn{2}{|c|}{ Odds of reporting ARD event } & \multicolumn{2}{|c|}{ Time-to-first ARD event } & \multicolumn{2}{|l|}{ Number of ARD events } \\
\hline & OR $(95 \% \mathrm{Cl})$ & $\mathbf{P}$ & HR $(95 \% \mathrm{Cl})$ & $\mathbf{P}$ & Incident rate ratio $(95 \% \mathrm{Cl})$ & $\mathbf{P}$ \\
\hline \multicolumn{7}{|l|}{ Entire cohort } \\
\hline White $(n=4999)$ & 0.91 (0.77 to 1.07 ) & 0.240 & 0.93 (0.84 to 1.04$)$ & 0.217 & 0.97 (0.86 to 1.10$)$ & 0.643 \\
\hline Black $(n=1864)$ & 1.09 (0.65 to 1.81$)$ & 0.754 & 1.18 (0.82 to 1.72$)$ & 0.375 & 0.89 (0.54 to 1.44$)$ & 0.626 \\
\hline White $(n=454)$ & $0.39(0.22$ to 0.69$)$ & 0.001 & 0.57 (0.38 to 0.85$)$ & 0.006 & 0.60 (0.40 to 0.91$)$ & 0.016 \\
\hline Black $(n=402)$ & 1.25 (0.48 to 3.21$)$ & 0.650 & 1.11 (0.55 to 2.34$)$ & 0.772 & 0.69 (0.28 to 1.74$)$ & 0.437 \\
\hline \multicolumn{7}{|c|}{ Those with emphysematous features } \\
\hline All races $(n=1907)$ & $1.10(0.83$ to 1.46$)$ & 0.522 & $1.05(0.90$ to 1.23$)$ & 0.546 & 1.03 (0.86 to 1.22$)$ & 0.766 \\
\hline
\end{tabular}

All effects expressed as those with MUC5B promoter polymorphism (GT and TT) compared with those without the polymorphism (GG).

Odds of reporting an ARD event assessed using logistic regression, time-to-first ARD event assessed using Cox regression and number of ARD events assessed using negative binomial regression.

All analyses presented are adjusted for age, sex, body mass index, current smoking status, pack years of smoking, per cent predicted FEV , a reported history of gastrooesophageal reflux disease, the total Saint George's Respiratory Questionnaire Score, the clinical centre and a reported history of an ARD in the year prior to study enrolment. ARD, acute respiratory disease.

Supplementary table E4). These findings were not present in those with emphysematous features (table 1 and online Supplementary table E4).

In NHW with the MUC5B promoter polymorphism ( $\mathrm{n}=948)$, interstitial features were associated with a lower odds of any ARD event (OR 0.57 ; 95\% CI 0.34 to $0.97, \mathrm{P}=0.037$ ) (online Supplementary table E5A). The presence of interstitial features had a similar effect when compared with the 'normal' subgroup, that is, those without emphysema (OR $0.44 ; 95 \%$ CI 0.23 to $0.85, \mathrm{P}=0.014$ ) (online Supplementary table E6A). In NHW participants, the presence of the MUC5B promoter polymorphism significantly interacted with interstitial features to reduce the odds of ARD events (adjusted P interaction $=0.016$ ) (online Supplementary table E7). This finding was present even when those with emphysema were excluded (online Supplementary table E8). By contrast, emphysematous features were associated with increased risk of most measures of ARD and this risk was not modified by the MUC5B polymorphism (online Supplementary tables E5B, E6B, E7-8).

Finally, in NHW participants who had $>5 \%$ of their lung occupied by interstitial features, those who had the MUC5B promoter polymorphism had a longer time-to-first ARD event than those without the polymorphism (HR 0.84; 95\% CI 0.72 to $0.99, \mathrm{P}=0.040)$, but did not have a statistically significant difference in their overall odds or number of ARD events (online Supplementary table E9).

\section{DISCUSSION}

In NHW ever-smokers in the COPDGene cohort with objective interstitial lung features, the presence of a MUC5B promoter polymorphism (rs35705950) was associated with a decreased odds of ARD events (both total and severe), a longer time-to-first event and fewer cumulative events. Additionally, the effect of interstitial CT features on the odds of reporting an ARD event was significantly modified by the presence of the polymorphism. These effects were specific to interstitial features and did not appear to be due to the concomitant presence of emphysema.
The prevalence of this polymorphism in certain racial groups raises the question of whether it may have a beneficial effect. ${ }^{1}$ Given the importance of MUC5B in mucociliary clearance and airway defence, one potential benefit the polymorphism may confer is a decreased risk of respiratory episodes such as ARD events. ${ }^{4}$ In the healthy human respiratory tract, MUC5B is the predominant component of secreted mucus, but the relative concentrations of it and the next most abundant mucin, MUC5AC, vary in disease. ${ }^{8}$ For instance, in COPD, although MUC5B still predominates and both MUC5B and MUC5AC increase with disease severity, the proportional increase in MUC5AC is far greater than that of MUC5B. ${ }^{6}$ Additionally, in asthma, an increase in MUC5AC and a relative decrease in MUC5B produces a MUC5AC-dominated mucus, which is associated with impaired mucus transport and may contribute to the viscous plugs. ${ }^{9}$ Therefore, one plausible possible mechanism for our findings is that the polymorphism, which results in increased expression of MUC5B, helps to normalise the MUC5AC to MUC5B ratio and therefore improves airway clearance (figure 1).

It should be stressed that our findings are preliminary and should be interpreted with caution. Further work using bronchoscopic, sputum, nasopharyngeal and/or peripheral blood samples is needed to verify that CT interstitial features represent phenotypic evidence of increased MUC5B expression and to determine whether increased expression is causally related to fibrosis. Additional work will also be needed to confirm our findings, especially given our use of a significance threshold of 0.05 in the setting of multiple analyses and to evaluate for inadvertent confounding, that is, that the polymorphism is not beneficial, but rather that alternative genetic and clinical factors that also induce interstitial features are simply more harmful. Similarly, our primary results may be biased due to conditioning on a common effect in our multivariable models. ${ }^{10}$ However, as there was little change in the results in the secondary analyses only adjusted for covariates unrelated to genetic status, this is unlikely to be the case (online Supplementary table E10). Future replication of our primary findings, combining independent cohorts and/or utilising cohorts with higher event 


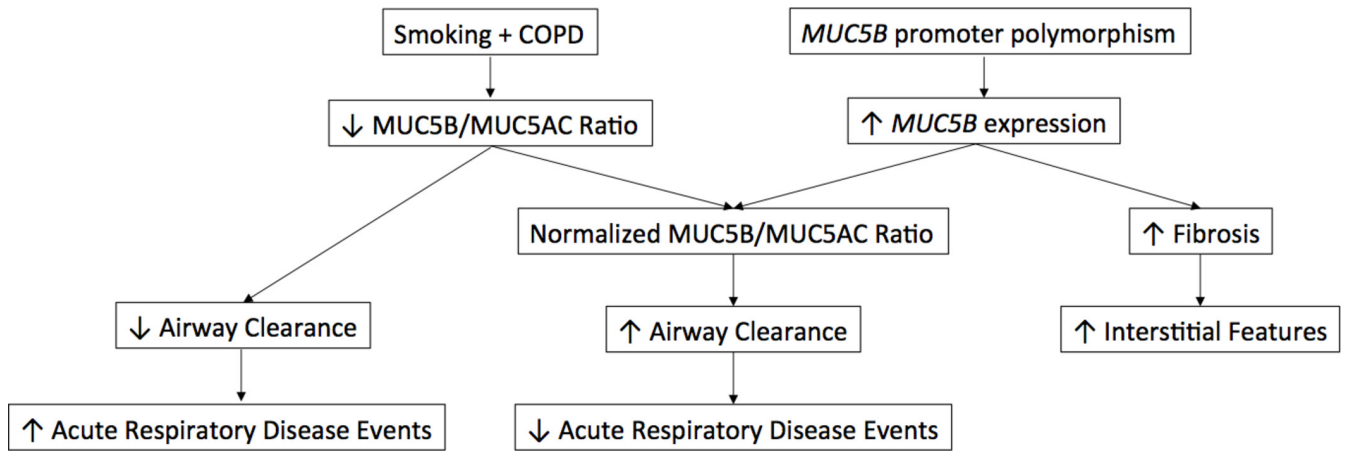

Figure 1 Proposed schema for the relationship between the MUC5B promoter polymorphism, interstitial features and ARD events. Note that we hypothesise that those individuals with interstitial features are those with the greatest evidence of increased $M U C 5 B$ expression and therefore those most likely to have the normalised MUC5B/MUC5AC ratio. ARD, acute respiratory disease.

rates, is also needed to overcome additional limitations such as the lack of associations seen between the polymorphism and outcomes in African-American participants. Additional replication in cohorts of never-smokers and those with more advanced fibrotic disease is needed as well. Finally, longer term studies investigating which individuals with the polymorphism go on to develop advanced pulmonary fibrosis are also needed.

In summary, we found that in ever-smokers with objective interstitial features on chest CT, a specific single-nucleotide polymorphism (rs35705950) in the promoter of the gene that encodes mucin 5B was associated with reductions in multiple measures of ARD events, a major driver of COPD death and disability. Future studies are needed to replicate these findings in other population and to continue to investigate their pathophysiological mechanisms.

\section{Author affiliations}

'Department of Medicine, Division of Pulmonary and Critical Care Medicine, Brigham and Women's Hospital, Boston, Massachusetts, USA

${ }^{2}$ Department of Radiology, Laboratory of Mathematics in Imaging, Brigham and Women's Hospital, Boston, Massachusetts, USA

${ }^{3}$ Department of Medicine, Weil Cornell Medical College, New York, USA

${ }^{4}$ Department of Medicine, Division of Pulmonary, Critical Care and Sleep Medicine, National Jewish Health, Denver, Colorado, USA

${ }^{5}$ Department of Medicine, Division of Rheumatology, National Jewish Health, Denver, Colorado, USA

${ }^{6}$ Department of Internal Medicine, Division of Pulmonary and Critical Care Medicine, University of Michigan, Ann Arbor, Michigan, USA

${ }^{7}$ Department of Internal Medicine, VA Ann Arbor Healthcare System, Ann Arbor, Michigan, USA

${ }^{8}$ Department of Medicine, Marisco Lung Institute, University of North Carolina, Chapel Hill, North Carolina, USA

${ }^{9}$ Department of Radiology, Brigham and Women's Hospital, Boston, Massachusetts, USA

${ }^{10}$ Department of Radiology, National Jewish Health, Denver, Colorado, USA

Collaborators The COPDGene Investigators: James D. Crapo MD, Edwin K. Silverman MD PhD, Barry J. Make MD, Elizabeth A. Regan MD PhD, Jeffrey L. Curtis MD, Carlos H. Martinez MD MPH, Lisa McCloskey BBA RRT, Perry G. Pernicano MD, Nicola A. Hanania MD MS, Philip Alapat MD, Mustafa Atik MD CCRP, Venkata Bandi MD, Laura Bertrand RN RPFT, Aladin Boriek PhD, Kalpalatha Guntupalli MD, Elizabeth Guy MD, Veronica V. Lenge de Rosen MD, Amit D. Parulekar MD, Dawn L. DeMeo MD MPH, Lystra P. Hayden MD, Craig P. Hersh MD MPH, Brian D. Hobbs MD, Aimee Garciano, Cherie Maguire B.S., Francine L. Jacobson MD MPH, George R. Washko MD, R. Graham Barr MD DrPH, Casandra Almonte, John H.M. Austin MD, Belinda M. D'Souza MD, Gregory D.N. Pearson MD, Michael Sheffey, Byron Thomashow MD, Neil MacIntyre, Jr. MD, Linda Brown, H. Page McAdams MD, Lacey Washington MD, Robert A. Wise MD, Ferdouse Begum PhD, Robert Brown MD, Cheryl Clare, Teresa Concordia, Marie Daniel RN CCRP, Nadia N. Hansel MD MPH, Karen Horton MD, Meredith McCormack MD MHS, Nirupama Putcha MD MHS, Meagan Scott, Richard Casaburi PhD MD, Alessandra Adami PhD, Matt Budoff MD, Robert Cao, Deborah Cavanaugh, Leticia Diaz, Hans Fischer MD PhD, Renee Love Indelicato, Dong Li MD PhD, Carmen Lopez-Garcia, Janos Porszasz MD PhD, Harry B. Rossiter PhD, William Stringer MD, Miriam Urrutia, Chris H. Wendt MD, Brian Bell MD, Miranda Deconcini, Ken Kunisaki MD MS, Charlene McEvoy MD MPH, Joseph
H. Tashjian MD, Natalie Woodruff BS RRT, Marilyn G. Foreman MD MS, Eugene A. Berkowitz MD PhD, Steven Fair, Eric L. Flenaugh MD, Gloria Westney MD MS, Russell P. Bowler MD PhD, Debra Dyer MD, Jay Finigan MD, Andrew Hull, David A. Lynch MB, Jason Varasteh, Richard Rosiello MD, Kathy Allain, Mary Charpentier, Diane Kirk RN, Anne McDonald, David Pace MD, Gerard J. Criner MD, David Ciccolella MD, Francis Cordova MD, Chandra Dass MD, Gilbert D'Alonzo DO, Parag Desai MD, Dee Fehrle BSN MHA, Carla Grabianowski RN BSN, Michael Jacobs PharmD, Gayle M. Jones RN BSN CCRP, Steven Kelsen MD PhD, Victor Kim MDA. James Mamary MD, Nathaniel Marchetti DO, Aditi Satti MD, Kartik Shenoy MD, Robert Steiner MD, Alex Swift MD, Maria Vega-Sanchez MD, Mark T. Dransfield MD, Erica Anderson, William C. Bailey MD, Surya P. Bhatt MD, Stephanie Ford, Anand lyer MD, Merry-Lynn McDonald PhD, Hrudaya Nath MD, Gabriela Oates PhD, Sushil K. Sonavane MD, Mike Wells MD, Elizabeth Westfall MPH, Joe W. Ramsdell MD, Dagni Chuki, Tarek El Hajjaoui, Katie Kinninger RCP CCRC, Karl Perez, Xavier Soler MD PhD, Andrew Yen MD, Alejandro Comellas MD, Kaylene Crawford, Angie Delsing, Spyridon Fortis MD, Fozia Ghafoor Janet Keating, Cassandra Kennedy, John D. Newell Jr. MD, Debra O'Connell-Moore, Phyllis Pirotte, Amna Rizvi-Toner, Thomas Sardone, Kim Sprenger RN BS, Marlee Wallace, MeiLan K. Han MD MS, Gretchen Bautista, Craig J. Galban PhD, Mary Kay Hamby BS RRT RPFT, Ella Kazerooni MD Wassim Labaki MD, Fernando Martinez MD, Joanne Billings MD MPH, Tadashi L. Allen MD, Abbie Begnaud MD, Nate Gaeckle MD, Mary P. Lynch RRT, Frank Sciurba MD, Jessica Bon MD, Mary J. Bryner BS RRT RPFT, Divay Chandra MD MSc, Paula Consolaro CCRC, Carl R. Fuhrman MD, Rhonda Lincoln, Lizzie Stempkowski, Patricia A. Tomko BS RRT, Antonio Anzueto MD, Sandra G. Adams MD, Diego Maselli-Caceres MD, Karl McCloskey, Mario E. Ruiz MD, Harjinder Singh MD

Contributors The authors meet criteria for authorship as recommended by the International Committee of Medical Journal Editors. SYA, RH, RSJE and GRW designed the study and wrote the initial manuscript. SYA performed the statistical analyses. RH, JCR and RSJE wrote the feature detection algorithm. All authors contributed to the production of the final of the manuscript.

Funding This work was supported by NHLBI R01 HL089897 and R01 HL089856. The COPDGene study (NCT00608764) is also supported by the COPD Foundation through contributions made to an Industry Advisory Board composed of AstraZeneca, Boehringer-Ingelheim, GlaxoSmithKline, Novartis, Pfizer, Siemens and Sunovion. Additional funding for this work includes: National Institutes of Health grants: T32-HL007633 (SYA and RKP), R01-HL107246 (RH, RSJE and GRW), R01-HL116933 (RH, RSJE and GRW), R01-HL111024 (GMH), P01-HL114501 (GRW) and R01HL089856 (RSJE and GRW); VA Merit Review 101 CX000911 (JLC) as well as Boehringer-Ingelheim Pharmaceuticals (GRW) and Pulmonary Fibrosis Foundation IM Rosenzweig Junior Investigator Award (SYA). Drs SYA, RH, RKP and RSJE report no other relevant disclosures. Dr GMH reports consulting for Medna LLC and Gerson Lehrman Group and has served on a scientific advisory boards for Genentech and Boehringer-Ingelheim. Dr GRW reports other support from Genentech, GlaxoSmithKline, PulmonX, and Janssen. This study was funded by Boehringer Ingelheim.

Disclaimer Funding for this work included grants from The National Institutes of Health and Boehringer Ingelheim Pharmaceuticals Inc (BIPI). BIPI had no role in the design, analysis or interpretation of the results in this study. BIPI was given the opportunity to review the manuscript for medical and scientific accuracy as it relates to BIPI substances, as well as intellectual property considerations.

Competing interests SYA, RH, RKP and RSJE report no other relevant disclosures. GMH reports consulting for Medna LLC, and Gerson Lehrman Group, and has served on a scientific advisory boards for Genentech and Boehringer-Ingelheim. GRW reports other support from Genentech, GlaxoSmithKline, PulmonX, and Janssen.

Ethics approval The following Institutional Review Boards (IRB) approved the 
COPDGene study: Partners IRB, Ann Arbor VA Research IRB, Baylor University IRB, Columbia University Medical Center IRB, Duke University Health System IRB, Health Partners IRB, Johns Hopkins Medicine IRB, Harbor UCLA Medical Center IRB, Michael E DeBakey VA Medical Center IRB, Minneapolis VA Health Care System IRB, Morehouse School of Medicine IRB, National Jewish Health IRB, Temple University IRB, University of Alabama IRB, University of California San Diego Human Research Protections Program, University of lowa IRB, University of Michigan Medical School IRB, University of Minnesota IRB, University of Pittsburgh IRB, Office of the IRB University of Texas Health Science Center San Antonio.

Provenance and peer review Not commissioned; externally peer reviewed.

Data sharing statement Data from the COPDGene Study are made available centrally by the data coordinating center.

(c) Article author(s) (or their employer(s) unless otherwise stated in the text of the article) 2018. All rights reserved. No commercial use is permitted unless otherwise expressly granted.

\section{REFERENCES}

1 Seibold MA, Wise AL, Speer MC, et al. A common MUC5B promoter polymorphism and pulmonary fibrosis. N Engl J Med 2011;364:1503-12.
2 Hunninghake GM, Hatabu H, Okajima Y, et al. MUC5B promoter polymorphism and interstitial lung abnormalities. N Engl J Med 2013;368:2192-200.

3 Ash SY, Harmouche R, Putman RK, et al. Clinical and genetic associations of objectively identified interstitial changes in smokers. Chest 2017;152:780-91.

4 Roy MG, Livraghi-Butrico A, Fletcher AA, et al. Muc $5 b$ is required for airway defence. Nature 2014;505:412-6.

5 Peljto AL, Zhang Y, Fingerlin TE, et al. Association between the MUC5B promoter polymorphism and survival in patients with idiopathic pulmonary fibrosis. JAMA 2013;309:2232-9.

6 Kesimer M, Ford AA, Ceppe A, et al. Airway mucin concentration as a marker of chronic bronchitis. N Engl J Med 2017;377:911-22.

7 Bowler RP, Kim V, Regan E, et al. Prediction of acute respiratory disease in current and former smokers with and without COPD. Chest 2014;146:941-50.

8 Thornton DJ, Rousseau K, McGuckin MA. Structure and function of the polymeric mucins in airways mucus. Annu Rev Physiol 2008;70:459-86.

9 Bonser LR, Zlock L, Finkbeiner W, et al. Epithelial tethering of MUC5AC-rich mucus impairs mucociliary transport in asthma. J Clin Invest 2016;126:2367-71.

10 Cole SR, Platt RW, Schisterman EF, et al. Illustrating bias due to conditioning on a collider. Int J Epidemiol 2010;39:417-20. 